\title{
The Influence of Athlete Students' Psychological Capital on Track and Field Performance
}

\author{
M. Jannah, E. Mintarto, Nurhasan, R. Widohardhono \\ Universitas Negeri Surabaya \\ Surabaya, Indonesia
}

\begin{abstract}
This study aims to know the correlation between students' psychological capital on track and field performance. The subjects of this study were 18 athletes who still studied in Senior High School in East Java. The adapted Psychological Capital Questionnaire for sport was constructed by Luthans, et al. (2007). The product moment method is utilized for statistic analyzing. The result of data analysis was 0.473 , meaning that the psychological capital variable influences the individual performance on track and field. The variable influenced $47.3 \%$ of the athlete's performance. Therefore, it can be concluded that track and field athletes must join the psychological coaching in order to develop their performance.
\end{abstract}

Keywords—psychological capital; athletes students; sport

\section{INTRODUCTION}

Athlete student is a student who participates in sport competitions to get achievement or who does physical exercise to get strength, stamina, speed, agility and balance to prepare themselves before the competition begins.

Malisoux et al. (2006), stated that physical, technical, tactical, and psychological factors will influence athlete students' performance [7]. Theoretically, the better physical, technical, tactical, and psychological condition, the better performance student athletes will achieve. Physical condition is one of the fundamental factors that ascertain the athlete's accomplishment [2]. The victory is often determined by psychological factor, although all of the athlete students have the same proficiency in track and field performance [7].

Luthans, Youssef, \& Avolio, (2007) stated that Psychological capital is the development of individual's positive psychological condition characterized as follows: (1) having selfefficacy to succeed at challenging tasks; (2) being optimistic in succeeding now and in the future; (3) being persistent to reach goals and, have an expectation to succeed; and (4) when having problems and obstacles, keeping resilience to attain success is necessary [6].

In psychological capital research, the performance has been the most widely researched and classified into some types such as: creative tasks, sales, referrals, manufacturing quality and quantity, watchdog values, and some sample characteristics; cross section, service, manufacturing, and highly educated. Theoretically, being consistent is the mechanism in psychological capital component as individual motivation and effort to succeed in increasing performance output. The research designated, stated that comprehensive performance model are devided into eight dimensions such as [3]; (1) job specific task proficiency, (2) non-job-specific task proficiency, (3) written and oral communications, (4) demonstrating effort, (5) maintaining personal discipline, (6) facilitating peer and team performance, (7) supervision/leadership, and (8) management/ administration. In this case, PsyCap relates to performance through demonstrating the efforts. Thus, when employees try harder to succeed, their performance is better. Motivation is not performance predictor, nevertheless, Campbell and colleagues (1993) argued that this is a very important predictor [3]. Higher individuals in psychological capital tend to be energized and put forward effort in higher performance over long periods. The students with higher efficacy apply efforts and believe that they can achieve it because they have a strong will. As the result, they have many solutions to their problems, such as; make internal attributions and have positive expectations about outcomes (optimism), and respond positively and diligently in adversity and resilience. Based on the explanation above, psychological capital should motivate students or being optimistic to successfully achieve goals and tasks that lead to get better performance than those in PsyCap before. Therefore, this current study focuses on the influence psychological capital on track and field performance.

\section{METHOD}

This study used a quantitative approach [10]. The subjects were 18 athlete students consist of 10 males, 8 females. Psychological capital assessed by using Psychological Capital 
Questionnaire (PCQ). There are 24 PCQ items to measure 4 Psychological capital factors such as: hope, efficacy, resiliency, and optimism. Performance assessed by parameter test conducted by coach. Data analysis used product moment analysis.

\section{RESULTS AND DISCUSSION}

This research is able to give empirical proof that there is an influence between psychological capitals to track and field of athlete students' performance. The result showed that hope, efficacy, optimism, and resiliency have correlation with track and field student athletes' performance. The achievement is a manifestation of a series of proper understanding towards what has to be done, the appropriate skill needed and proficiency to be efficiently applied for the best solution during the competition $[5,9]$.

Hope is able to influence track and field of athlete students' accomplishment, where athletes are one who proactively generates one or more pathways to obtain accomplishment in a given situation. The result shows that efficacy has positive influence on track and field athlete students' accomplishment. Craft et al. (2003), and Luthan et al. (2007) also said that efficacy influenced athlete's performance [4,6]. Further, those athlete students are able to predict what action has to be done to reach optimum accomplishment. According to Bandura (1997) it is one of the important personality aspects in daily activities [1]. Self confidence can make someone behave appropriately to reach desired result.

According to Masten \& Reed (2002) the result indicates that resilience has a positive correlation with the performance that is characterized by positive adaptation patterns in the significant difficulties or risks that allow individuals to rise quickly and effectively from adverse events [8].

The athlete students require resilience to reduce emotions and negative tensions in a competition [13]. This ability can help athlete students to control emotions from various situations, both internal and external. It can be concluded that good emotional rules affect the movement of field athletes and student fields.

This study shows that optimism has a significant effect on the students' achievement. If field and field athletes have this positive expectation, they will continue to work although there are increasing difficulties.

Therefore, it can be concluded that psychological capital (consisting of hope, efficacy, resiliency, and optimism) effect the track and field athlete students' accomplishment. The higher psychological capital athlete students have during competition, the more accurate and effective performance they do to gain the optimal result. There are several suggestions:

1. For the Indonesian Official Athletic Organization. Training programs for track and field athlete students should be based on integrated psychological factor, through :

a. The use of psychological capital factor as measurement to identify athlete's ability (to complete physical factor) in the beginning of intensive training.

b. To place athletes into groups based on psychological capital factor, to design and recommend appropriate psychological skill for the athletes.

c. Evaluate the competence of psychological capital factor to complete physical parameters before and during competition.

2. Training program is based on psychological capital aspects needed to complete physical exercise, nutritious intake, and to optimize their performance. The recommended program is emotional regulation training.

3. Track and field athlete students should understand psychological capital factors influencing the target performance and increase the psychological factors through appropriate training programs.

4. For the next researchers :

a. This study adapted psychological capital Questionnaire from Luthan et al (2007). It should be evaluated to get psychological capital factor data from subjects [6]. It is possible that the measurement has limitations, so that self-report is needed to complete the data directly from the other person.

b. The use of psychological capital can be used as sample cluster, such as to test psychological capital for junior track and field athlete students.

\section{CONCLUSION}

In conclusion, it shows that track and field athlete students' performance have correlation with psychological capital. In other word, having high psychological capital can potentially 
achieve optimum performance. Therefore, mental training for increasing psychological capital is highly needed.

\section{REFERENCES}

[1] A. Bandura, Self-efficacy: The exercise of control, New York: Freeman, 1997.

[2] T. O. Bompa, and G. G. Haff, Periodization: Theory and methodology of training. 5th Edition, Champaign, IL: Human Kinetics, 2009.

[3] J. P.Campbell, R. A. McCloy, S. H. Oppler, and C. E. Sager, A theory of performance. In N. Schmitt and W. C. Borman (Eds.), Personnel selection in organizations (pp. 35-70). San Francisco, CA: Jossey-Bass, 1993.

[4] L.L. Craft, I.M. Magyar, B.J. Becker and D.L. Feltz, "The relationship between the competitive state anxiety inventory-2 and sport performance: A meta-analysis," Journal of Sport \& Exercise Psychology, vol. 25, no.1, pp. 44-65, 2003.

[5] G. Jones, "What is this thing called mental toughness? An investigation of elite sport performers," Journal of Applied Sport Psychology, vol. 14, no. 3, pp. 205-218, 2002.

[6] F. Luthans, , C. M. Youssef, and B. J. Avolio, Psychological capital: Developing the human competitive edge, Oxford, United Kingdom: Oxford University Press, 2007.

[7] L. Malisoux, H. Francaux, D. Theisen, "Strech-shortening cycle exercises: An effective training paradigm to enhance power output of human single muscle fibers," Journal Applied Physiology, vol. 100, no. 3, pp. 771-779, 2006.

[8] A. S. Masten, and M.G. J. Reed, Resilience in development. In C. R. Snyder \& S. J. Lopez (Eds.), Handbook of positive psychology (pp. 7488). Oxford, United Kingdom: Oxford University Press, 2002.

[9] J.S. Raglin, Psychological factors in sport performance: The mental health model, 2001.

[10] H.G. Jones, Plants and microclimate: a quantitative approach to environmental plant physiology, Cambridge university press, 2013.

[11] F. Luthans, B.J. Avolio, J.B. Avey, and S.M. Norman, "Positive Psychological Capital: Measurement and Relationship with Performance and Satisfaction," Leadership Institute Faculty Publications, 11, 2007.

[12] G. Görgens-Ekermans and M. Herbert, "Psychological capital: Internal and external validity of the Psychological Capital Questionnaire (PCQ24) on a South African sample," SA Journal of Indutrial Psychology, vol. 39, no. 2, 2013.

[13] X. G. Secades, et. al, "Relationship Between Resilience and Coping Strategies in Competitive Sport,", Journals Permissions, vol. 122, no. 1, pp. 336-349, 2016.

[14] H.D. Simons, D.V. Rheenen, M.V. Covington, "Academic Motivation and the Student Athlete," Journal of College Student Development, vol. 40, no 2, 1999.

[15] C. Crowley, Factors Influencing College Choice AmongTrack and Field Student Athletes at NCAA D-1 Conference HBCUs, Dissertation, Department of Sport Management, Recreation Management, and Physical Education of Florida State University, 2004. 